\title{
Stress of working abroad: a systematic review
}

\author{
Shotaro Doki ${ }^{1,2} \cdot$ Sinichiro Sasahara ${ }^{2} \cdot$ Ichiyo Matsuzaki $^{2,3}$
}

Received: 14 October 2017 / Accepted: 26 June 2018 / Published online: 2 July 2018

(c) The Author(s) 2018

\begin{abstract}
Purpose Many companies target international markets to expand their business. Companies need to manage international teams with a wide variety of skills, knowledge and values to run their business effectively; however, there are many issues of acculturation stress. Not only business travellers and expatriates, but also immigrant workers have issues adjusting to foreign culture. The aim of the present study is to identify the stress factors affecting foreign-born workers via a systematic review. Methods The systematic review was conducted using PubMed, PsycINFO, Embase and Cochrane Library databases. Articles on the subject of workers living abroad, such as immigrants, expatriates and business travellers, were included. The risk of bias in the included articles was assessed using the Cochrane Collaboration's tool for assessing risk of bias for randomised controlled trials (RCTs), RoBANS for non-RCT studies, and CASP for qualitative studies.

Results For the systematic review, 45 out of 14,994 articles were analysed. Six components, communication, cultural differences in the workplace, daily life, relationships with family and colleagues, financial problems and social inequality, were extracted.

Conclusion Foreign-born workers are suffering from acculturation and occupational stress. The results of the present study can help greatly with understanding of the stress structure of working abroad.
\end{abstract}

Keywords Acculturation $\cdot$ Business travellers $\cdot$ Expatriates $\cdot$ Immigrants $\cdot$ International assignment

\section{Introduction}

In recent times, many professional people have travelled abroad to work; for example, the number of business visits to the UK was 8.3 million in 2014 (Office for National Statistics 2015). Many companies target international markets; therefore, they send workers to foreign countries. Expanding business is an advantage of globalisation; in contrast, the issue of acculturation for workers has occurred. Premature return from international assignment due to failure to adjust to the foreign culture is a heavy burden for the

Electronic supplementary material The online version of this article (https://doi.org/10.1007/s00420-018-1333-4) contains supplementary material, which is available to authorized users.

Shotaro Doki

doki.s@md.tsukuba.ac.jp

1 Institute of Psychiatry, Psychology and Neuroscience, King's College London, London, UK

2 Faculty of Medicine, University of Tsukuba, Tsukuba, Japan

3 International Institute for Integrative Sleep Medicine, University of Tsukuba, Tsukuba, Japan company because international assignment has higher cost than domestic assignment. Expatriates experience huge cultural differences between their home countries and host countries. Not only expatriates, but also immigrant workers have issues adjusting to foreign culture. They have to greatly change their lifestyle when adjusting to host countries; consequently, many stressful social adjustment problems occur (Cervantes et al. 1991, 2016).

For foreign-born workers, living and working in the host country is more stressful than for native workers. They need to stay in a country which has a different cultural background than they are used to. Working abroad requires adjustment to the host country. There are several pieces of the literature that suggest migrants have less professional support, decreased well-being and experience more mental ill-health compared to native workers (Font et al. 2012; Aalto et al. 2014). Psychological stress can lead to depression and adjustment disorders, which results in suicidal thought and premature return intention (Wang and Takeuchi 2007; AlMaskari et al. 2011). It is important for foreign workers to elucidate the psychological symptoms and stress factors that affect them when working abroad. 
There are many pieces of literature about cross-cultural psychology. According to Lysgaard (1955) and Gullahorn and Gullahorn (1963), there are several steps required for people to adapt to a foreign society. Cross-cultural adjustment is often described as acculturation, which means the processes and consequences of psychological and cultural contact between one culture and another culture (Berry 1997). Berry (1997) categorised acculturation into four types: integration, assimilation, separation, and marginalisation. However, Berry's theory does not cover all cases of acculturation. Acculturation has many forms which relates to different phenomena and processes. Lazarus (1997) suggested that Berry's theory was too broad and abstract to describe the framework of acculturation.

There are two studies which have evaluated the adjustment of working abroad. According to Bhaskar-Shrinivas et al. (2005), some paradoxical findings remain and need to be refined. They suggested that the centrality, criticality, and complexity of expatriate adjustment are crucial. Hechanova et al. (2003) suggested that expatriate adjustment is related to job strain, job satisfaction, organisational citizenship, intent to turnover, and job performance. From these studies, the concept of adjusting foreign workplaces has been established. However, how stress and mental disorder are affected by working abroad had not been sufficiently evaluated.

The relationship between acculturation and psychological stress has been controversial (Shen and Takeuchi 2001), and there are three, negative, positive, and curvilinear, relationships between acculturation and psychological stress (Rogler et al. 1991). Acculturation was related to both positive and negative psychological stress directly or indirectly through factors such as social support, personality, and perceived health (Shen and Takeuchi 2001). Mendenhall and Oddou (1985) anecdotally suggested that four dimensions are related to successful international assignments for workers: self-oriented, others-oriented, perceptual, and cultural-toughness. As a theoretical framework, Black et al. (1991) suggested a model of acculturation which has five factors, individual, job, organisational culture, organisational socialisation and non-work, related to the degree of adjustment. Another study that surveyed international assignees suggested that the factors in success are family situation, flexibility and adaptability, job knowledge and motivation, relational skills, and extracultural openness (Arthur et al. 1995). Adams and van de Vijver (2015) also reported that expatriates' stress depends on their cultural distances, support, and purpose, which are also related to the organisational intention for the international assignment. The integration of previous findings is shown in Table 1.

So far, there are many studies assessing foreign-born workers; however, the subjects or workplaces are limited to specific nationalities or countries. There have been miscellaneous findings since by applying a stressor model acculturation is limited to reactive adjustment to proximal, situational variables neglecting long-term proactive personal (re)development. These studies cannot comprehensively evaluate the theoretical framework of a wide variety of workers and workplaces. The present study aims to assess the factors that deteriorate and mitigate stress amongst workers living abroad by conducting a systematic review. The factors intervening on the relationship between acculturation on the one hand, and stress, and work adjustment on the other hand were searched. Based on the previous cross-cultural adjustment model, to understand the stress structure of working abroad, we focussed on the conceptualisation of acculturation. The hypothesis is that "There are specific factors that either deteriorate or mitigate stress for foreign workers". This study protocol was registered with PROSPERO (the registration number is: CRD42015029315).
Table 1 Four types of factors related to international adjustment or acculturation (based on earlier research)

\begin{tabular}{|c|c|c|c|}
\hline \multicolumn{4}{|c|}{ Theoretical framework } \\
\hline Individual & Occupational & Support & Cultural \\
\hline \multicolumn{4}{|c|}{ Mendenhall and Oddou (1985) } \\
\hline $\begin{array}{l}\text { Self-oriented } \\
\text { Perceptual }\end{array}$ & - & Others-oriented & Cultural toughness \\
\hline \multicolumn{4}{|l|}{ Black et al. (1991) } \\
\hline Individual & $\begin{array}{l}\text { Job } \\
\text { Organisational culture }\end{array}$ & $\begin{array}{l}\text { Organisational } \\
\text { Socialisation }\end{array}$ & $\begin{array}{l}\text { Non-work } \\
\text { Organisational culture }\end{array}$ \\
\hline \multicolumn{4}{|l|}{ Arthur et al. (1995) } \\
\hline $\begin{array}{l}\text { Relational skills } \\
\text { Flexibility } \\
\text { Adaptability }\end{array}$ & $\begin{array}{l}\text { Job knowledge } \\
\text { Motivation }\end{array}$ & Family situation & Extra-cultural openness \\
\hline \multicolumn{4}{|c|}{ Adams and van de Vijver (2015) } \\
\hline Purpose & - & Support & Cultural distances \\
\hline
\end{tabular}




\section{Methods}

\section{Search}

A flow diagram of PRISMA (Preferred Reporting Items for Systematic reviews and Meta-Analyses) recommendations was used to select studies (Liberati et al. 2009). Different databases were searched to determine what kind of stress foreign workers felt and what kind of interventions affected their stress levels. Search terms were selected using a PICO approach, which stands for Population, Intervention, Control and Outcome. We used the search terms "work", "international", "abroad" and "immigrant" for Population; "culture" and "adjustment" for Intervention; and "stress" and "mental disorder" for Outcome. Terms for Control were not included deliberately, because the number of controlled studies seemed to be small. The search was conducted on 8th November 2015. The PubMed, PsycINFO, Embase and Cochrane library databases were used to search for articles from 1st January 2000 to 8th November 2015. The search strategy is shown in supplementary A. An expert (SD) selected the articles and two experts (SD and SS) assessed them. First, duplicate articles were deleted from the four databases. Second, the titles/abstracts were assessed, and then relevant articles in full text were collected. Using the inclusion/exclusion criteria following, the full text articles were assessed. Finally, target articles were retrieved. A consensus meeting of three experts (SD, SS, and IM) resolved any disagreements between the two reviewers. We also referred to the bibliographies from retrieved articles.

\section{Inclusion and exclusion criteria}

We included articles whose subjects were workers in all three categories living abroad (immigrants, expatriates and business travellers). In terms of outcomes, we included the studies which were originally aimed at workers' stress and stress-related illness (e.g. depressive mood, fatigue, exhaustion, burnout, irritation, depression, anxiety and sleep disorder). When there were intervention studies, we included the ones with interventions that offered medication and psychological therapies aimed at reducing stress. We only selected articles written in English.

We excluded studies whose subjects were related to the military and veterans, workers engaged in transportation related to jet-lag (e.g. pilots, cabin attendants, ship crews and astronauts), students, and workers with severe mental illnesses such as psychosis. Articles with a low evidence level such as a conference papers, expert opinions, editorials, letters to the editor and commentary were excluded.

\section{Study bias and quality assessment}

The risk of bias of the included articles was assessed using Cochrane Collaboration's tool for assessing risk of bias for randomised controlled trials (RCTs) (Higgins and Green 2011). The risk of bias has seven domains: random sequence generation, allocation concealment, blinding of participants and personnel, blinding of outcome assessment, incomplete outcome data, selective reporting and other biases. Each domain was judged as low, high or unclear risk. For non-RCT studies, the risk of bias was assessed by the Risk of Bias Assessment tool for Non-randomized Studies (RoBANS) (Kim et al. 2013). It has six domains: the selection of participants, confounding variables, measurement of exposure, blinding of outcome assessments, incomplete outcome data and selective outcome reporting. Each domain was judged as low, high or unclear risk. For qualitative studies, the quality was assessed using the Critical Appraisal Skills Programme (CASP) (CASP 2013). The checklist has ten questions that help to assess the quality of each study. Each question was answered using "yes", "no", or "can't tell". When one or two of the first two questions were marked "no" or "can't tell", the study was branded as a low-quality study. Finally, a risk of bias table was drawn. The process was conducted independently by two experts (SD and SS). A consensus meeting resolved any disagreements between them.

\section{Results}

In total, 14,994 articles from the four databases were searched (Fig. 1). Next, duplicates, papers not written in English, conference papers, review articles, editorials, commentaries and dissertations were omitted. Titles and abstracts of 12,322 articles were assessed, and then the full texts of 86 articles were collected. From them, 45 articles were excluded, and finally 6 articles were added from the references of included articles. In total, 47 articles were included to assess their quality.

\section{Study designs}

Seven studies used a qualitative method; 33 studies used a quantitative method; 7 studies used a mixed model method. Among all the 47 retrieved studies, there was only 1 RCT. The assessments of risk bias or quality are shown in supplementary B, C, and D. One low-quality study in the part of qualitative study (Espino et al. 2002) and two studies with very high risk of bias (Deosthalee 2002; Zahid et al. 2003) were removed from the analysis. Finally, 45 studies were included in this review. The characteristics of the included studies are shown in Table 2. 
Fig. 1 Flow diagram of included studies

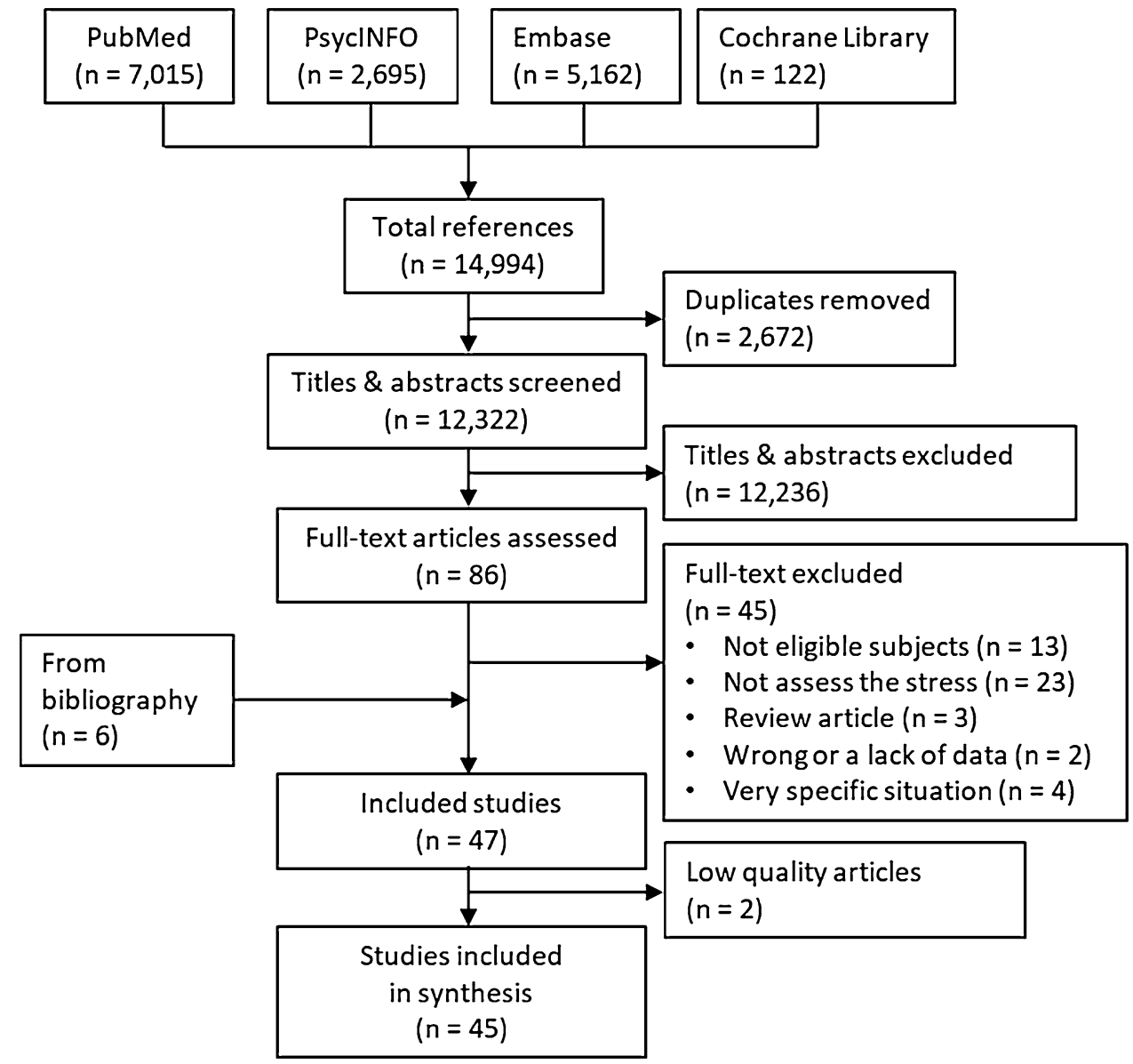

\section{Subjects}

Subjects are office, manual, healthcare, educational and agricultural workers. About $30 \%$ of studies surveyed expatriates. Two studies surveyed business travellers who had stayed in the host country for a short term. Other studies were about immigrants or did not show the duration of stay in the host country. The host country in about half of the studies was the US, and the subjects of these ten studies were from Latin America.

\section{The duration of stay}

There was a wide range of durations of stay, from less than 5 days to over 15 years.

The most frequent duration of business visits among surveyed workers at a US multinational corporation was $<5$ days/trip at 1-5 trips/year (Burkholder et al. 2010). The average duration of stay among business travellers at another US multinational corporation was 86.5 days (Espino et al. 2002).

A study about expatriates suggested that the length of stay in the host country was not associated with non-work adjustment (Stahl and Caligiuri 2005). The survey of a
German multi-site study also showed that the length of stay was not related to job satisfaction and stress (Stroppa and Spies 2011).

In terms of immigrants, consensus was not reached on the influence of the length of stay on work and acculturation stress. Studies suggested that permanent settlers among Mexican immigrants had better mental health (Alderete et al. 2001), and that the length of stay and acculturation had a positive correlation with job satisfaction (Ea et al. 2008). However, the length of stay in the US was positively associated with the elevation of norepinephrine levels among Filipino immigrant nurses or nurses' aides (Brown and James 2000).

\section{Stressors}

In the present study, the evidence level of each study was not high. Only one study was designed as an RCT and about one-third of the studies were qualitative. From the qualitative studies, the problems of foreign-born workers were reported, and then the six domains (communication, cultural differences in the workplace, daily life, relationships with family and colleagues, financial problems and social inequality) were decided. 


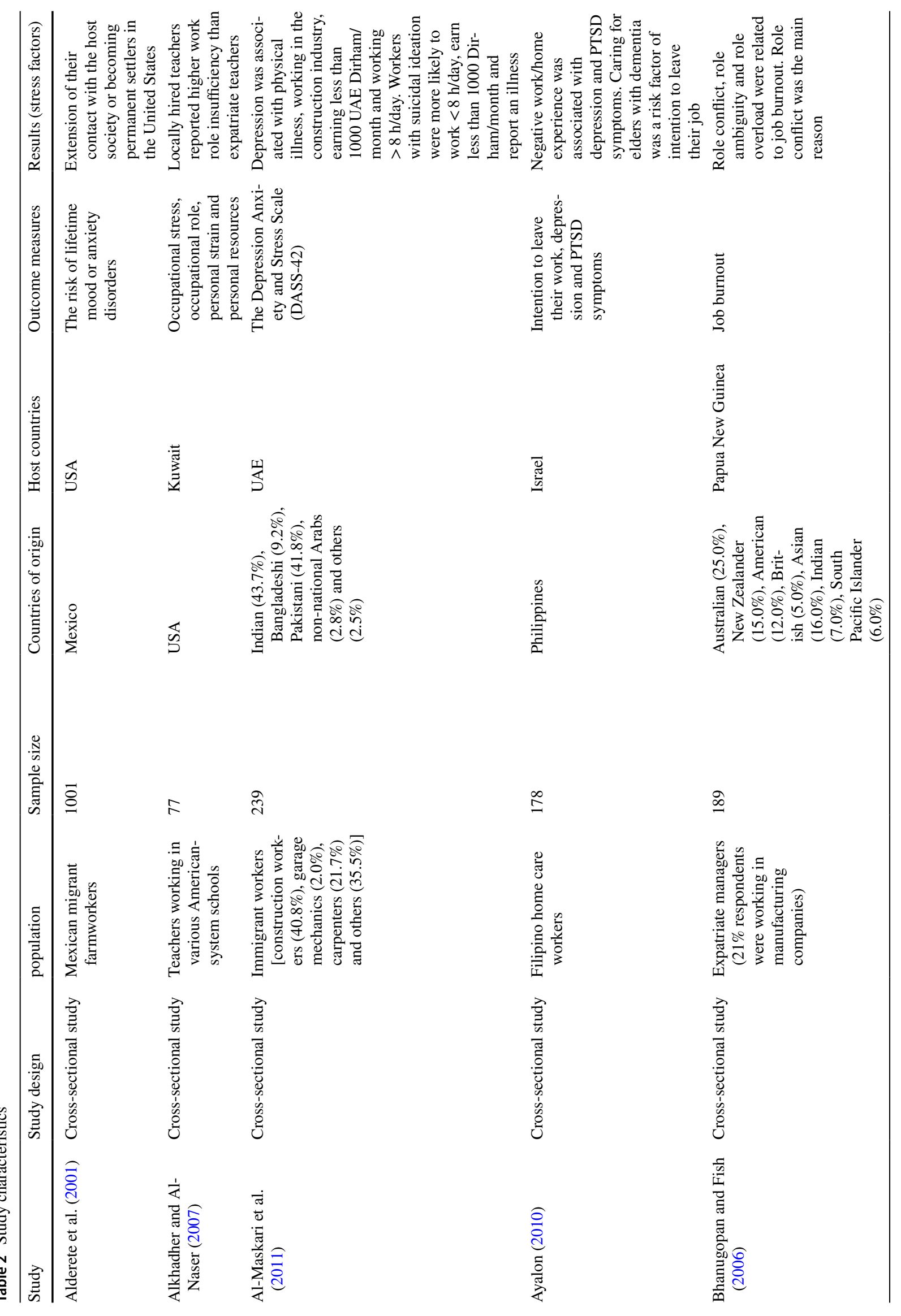




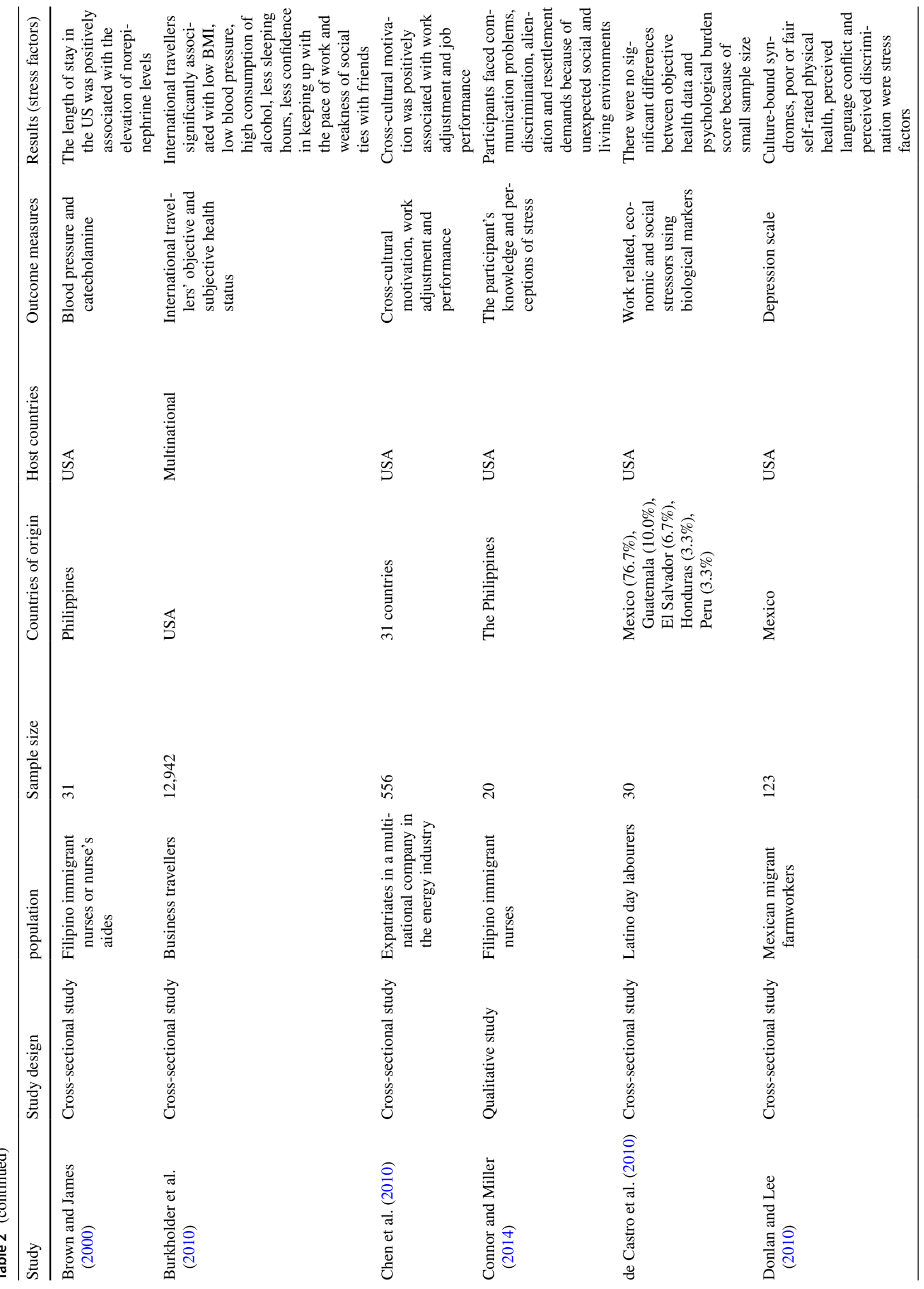




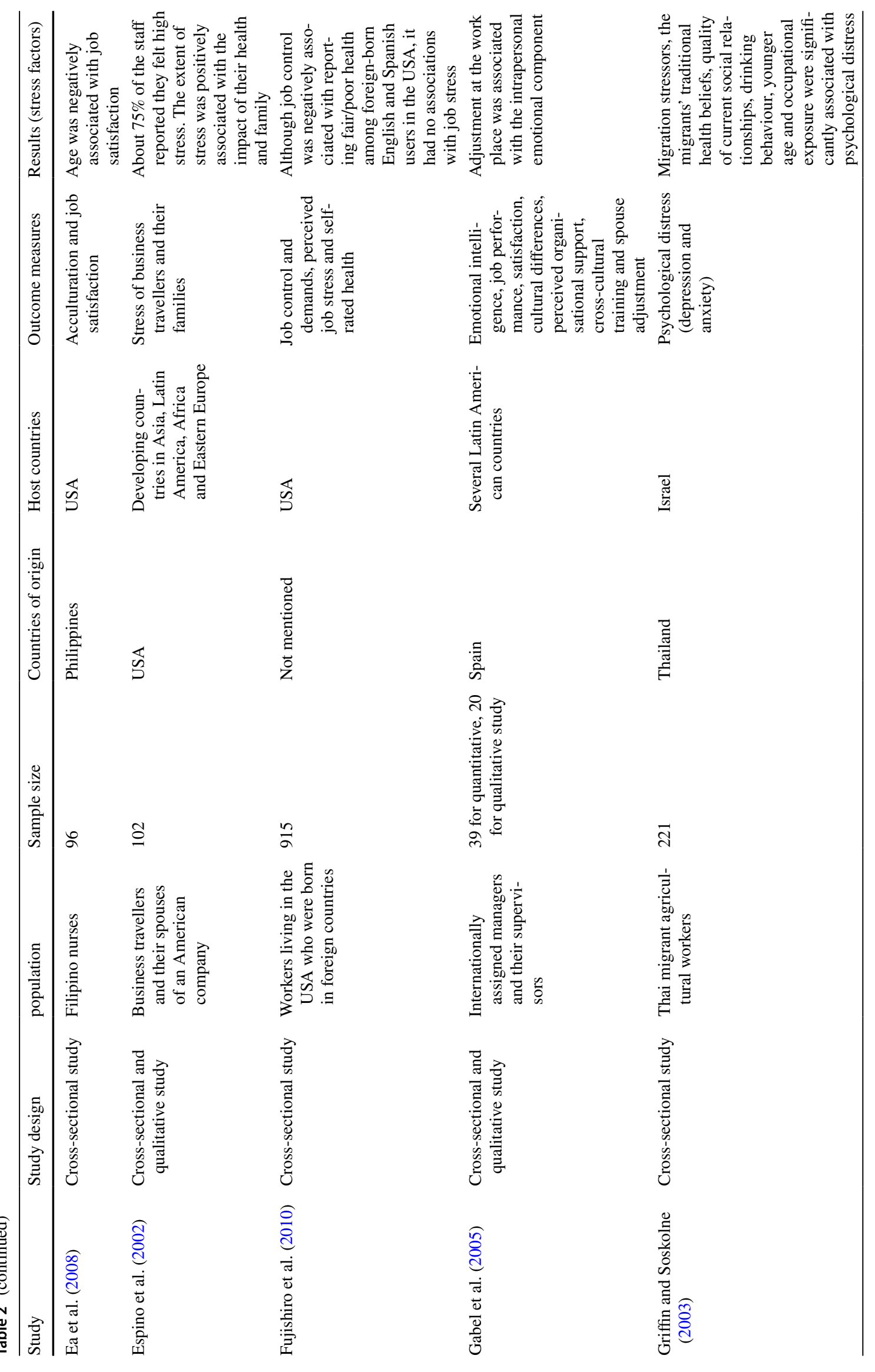




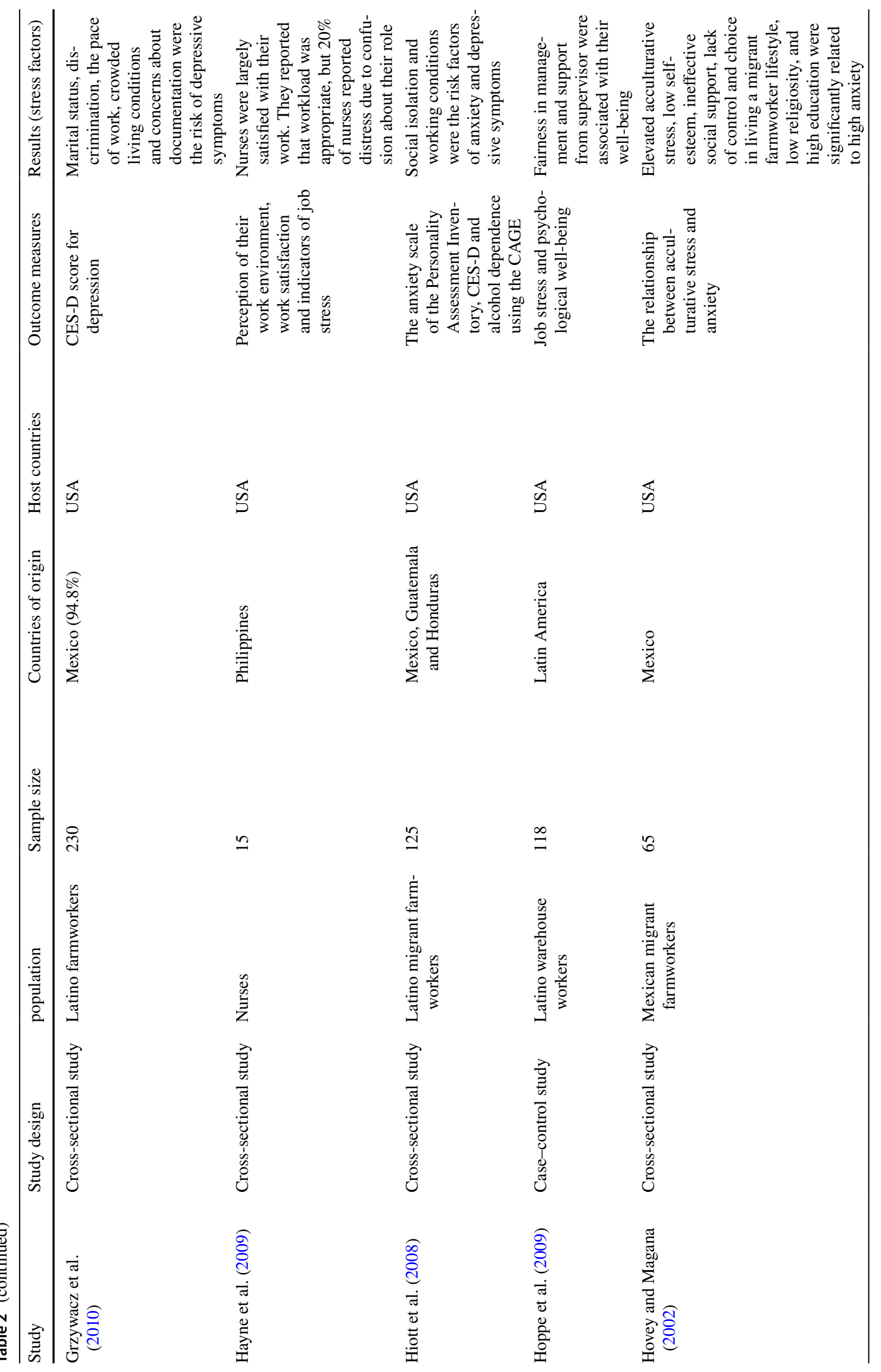


International Archives of Occupational and Environmental Health (2018) 91:767-784

775

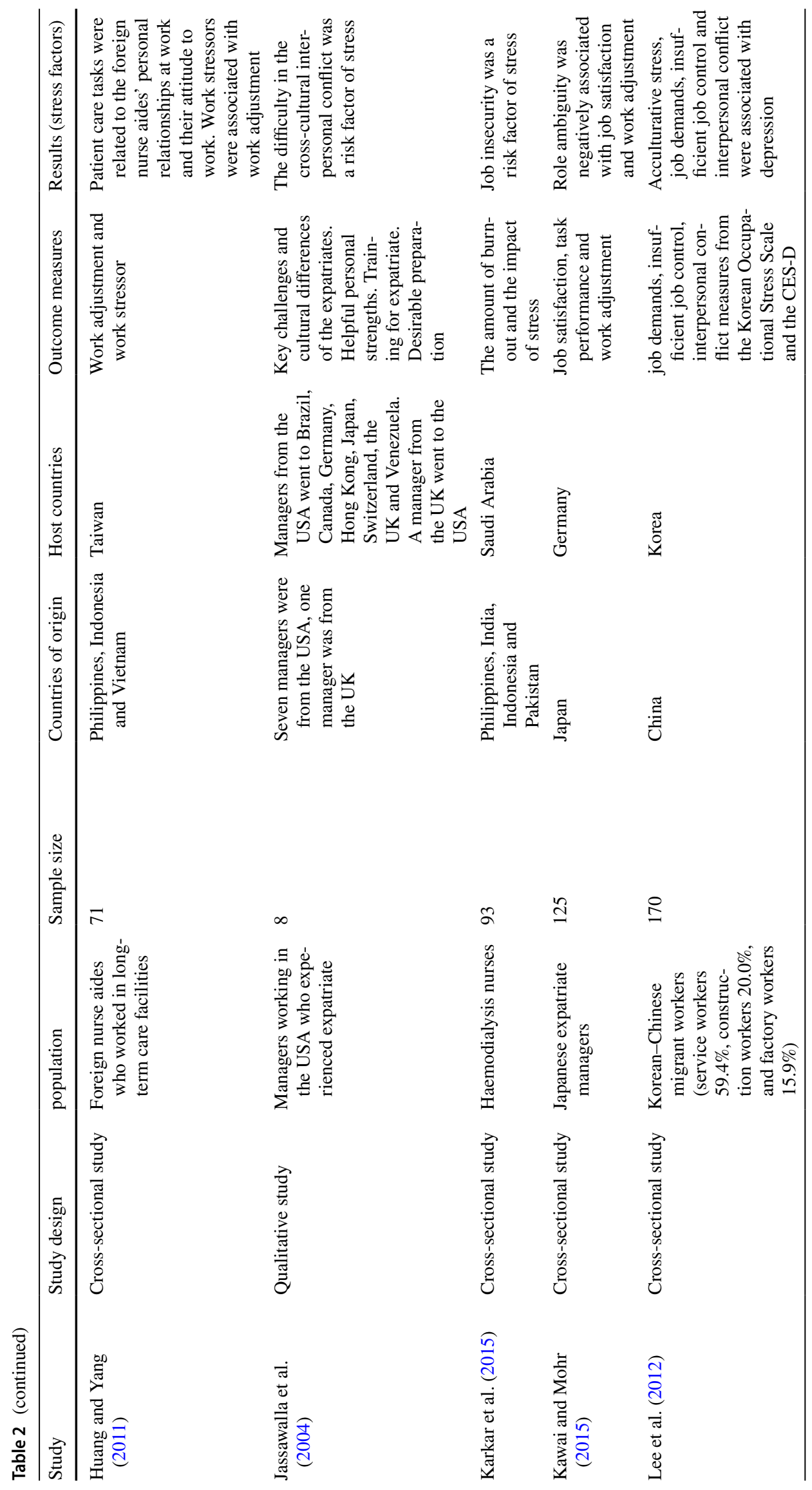

Springer 


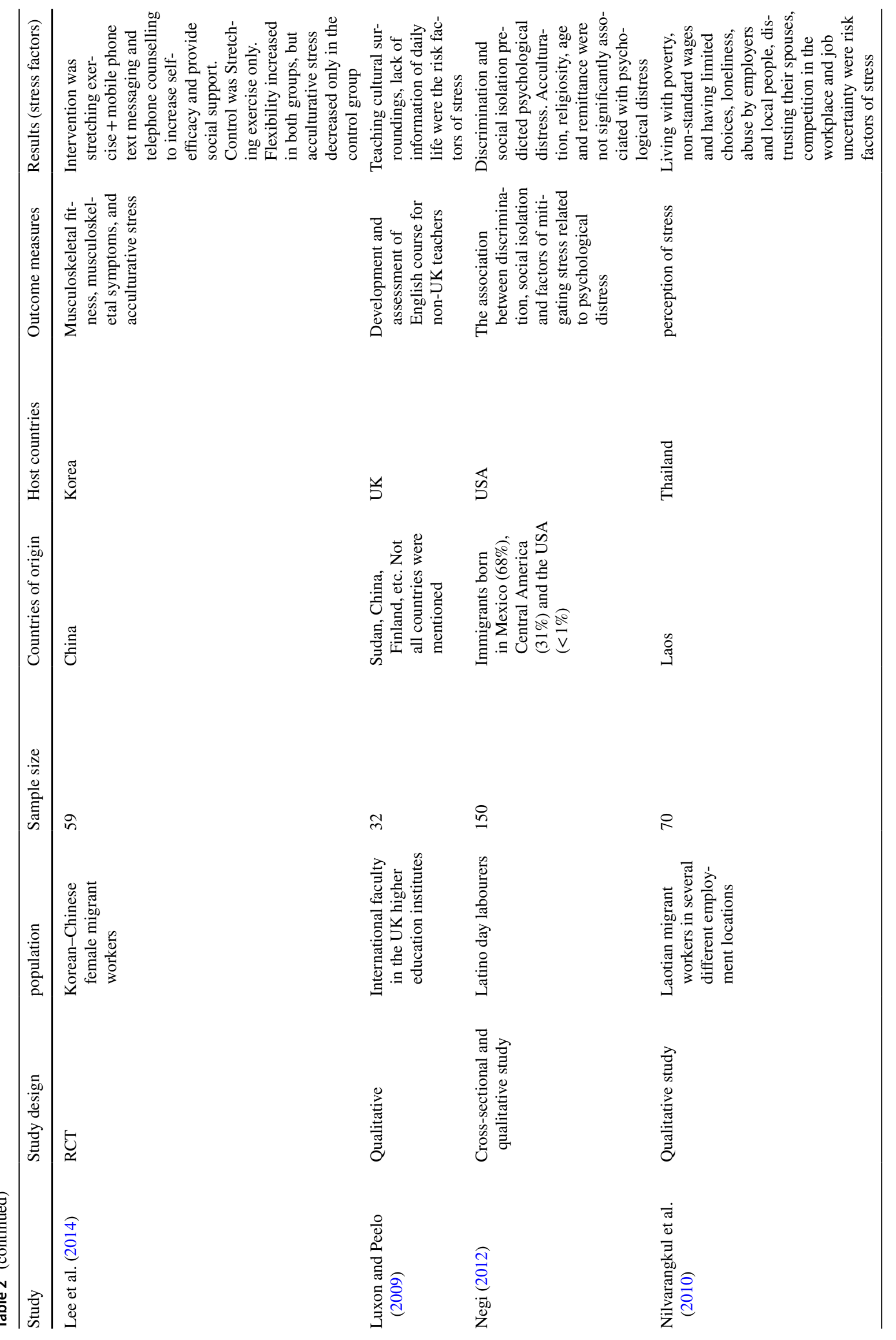




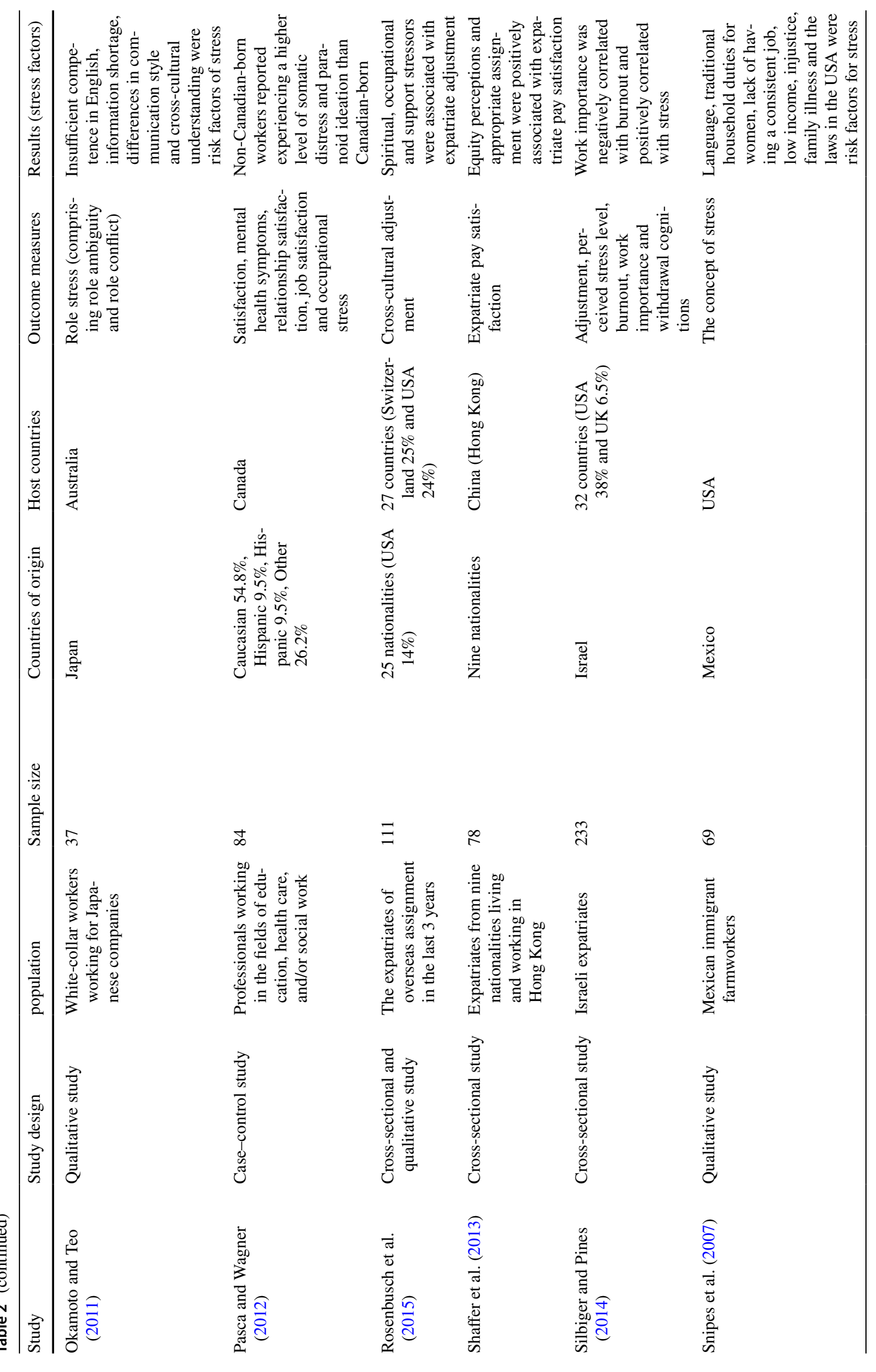




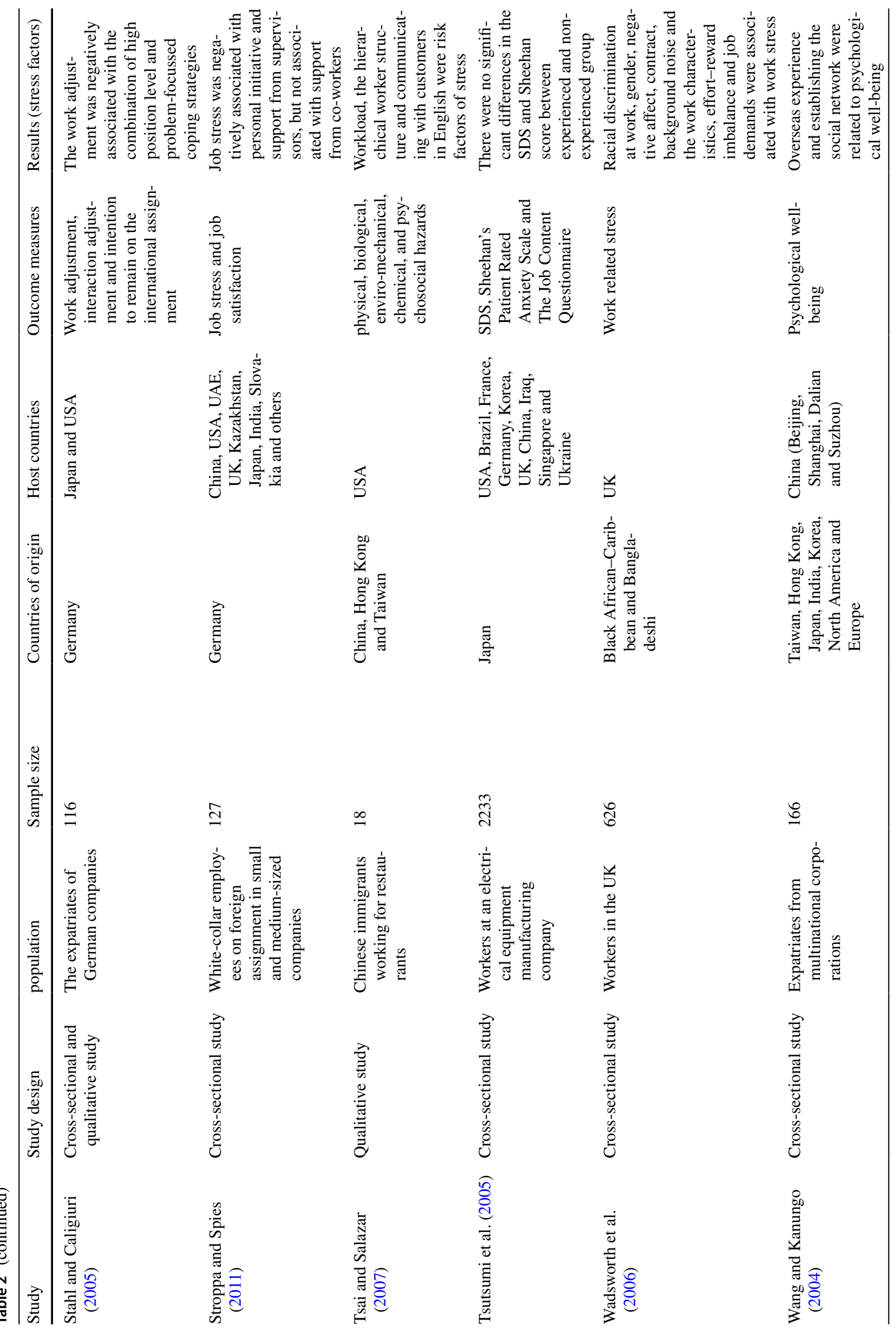




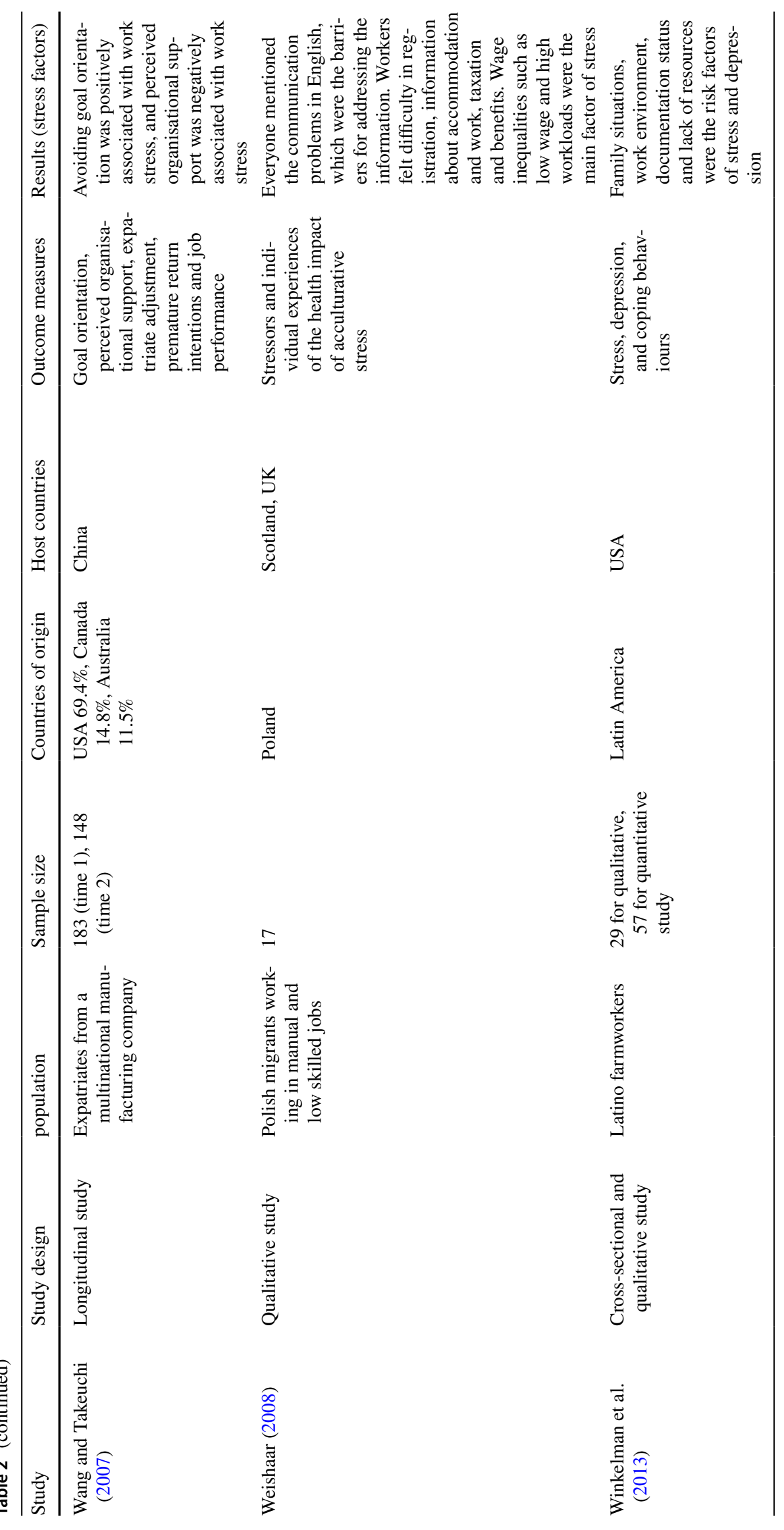




\section{Communication}

Language was a strong barrier to communication, which made it hard to address the information (Weishaar 2008). Expatriates felt frustration when facing a new language and had difficulty making new friends (Rosenbusch et al. 2015; Okamoto and Teo 2011). Chinese immigrants working for US restaurants reported that talking to customers in English was stressful (Tsai and Salazar 2007). Filipino nurses in the US also reported difficulty in communicating in English (Connor and Miller 2014).

According to two quantitative studies, language was not related to job satisfaction and stress (Grzywacz et al. 2010; Stroppa and Spies 2011). The ability to understand English and the state of their visas were not related to migrant farmworkers' stress (Grzywacz et al. 2010). However, perceived language conflict was one of the stress factors (Donlan and Lee 2010). Social isolation was also associated with psychological distress such as depressive and anxiety symptoms (Hiott et al. 2008; Griffin and Soskolne 2003). Establishing a social network was important to expatriates' well-being (Wang and Kanungo 2004).

\section{Cultural differences in the workplace}

Expatriates did not have enough time to learn about their new environment, and the change increased their stress levels (Rosenbusch et al. 2015). Their understanding of the cultural differences in education was more important for newly assigned foreign-born teachers in the UK than English training (Luxon and Peelo 2009).

The motivation to understand cross-cultural differences was positively associated with work adjustment and job performance (Chen et al. 2010). Expatriates' goal orientation was related to job performance (Wang and Takeuchi 2007). Perceived work importance was the mitigating factor in work stress (Silbiger and Pines 2014). Role conflict, role ambiguity and role overload were positively associated with job burnout and dissatisfaction (Bhanugopan and Fish 2006; Kawai and Mohr 2015). However, according to a study among teachers in Kuwait, locally hired teachers reported higher work role insufficiency than expatriate teachers (Alkhadher and Al-Naser 2007). Although job control was negatively associated with reporting fair/poor health among foreign-born English and Spanish users in the US, it had no associations with job stress (Fujishiro et al. 2010). In addition, high job demand and low job control affected the personal relationships and work motivations of foreign-born nurses' aides in Taiwan (Huang and Yang 2011).

\section{Daily life}

The balance between meeting an expectation at work and also at home was difficult (Rosenbusch et al. 2015). A sense of losing their language and culture was a stress factor for farmworkers in the US (Snipes et al. 2007). Family situations, work environment, documentation status and lack of resources were also stress factors for farmworkers in the US (Winkelman et al. 2013). It was recommended that information on accommodation and finance should be provided to newly assigned foreign-born teachers in the UK (Luxon and Peelo 2009).

International business travel correlated with increased alcohol consumption, difficulty in sleeping and less confidence in dealing with their work (Burkholder et al. 2010). In a Canadian study, non-Canadian-born immigrant workers reported a higher level of physical and psychological symptoms than Canadian-born workers (Pasca and Wagner 2012). Acculturation stress was also related to psychological problems (Lee et al. 2012), while low control and low religiosity among immigrant farmworkers were associated with anxiety (Gabel et al. 2005).

\section{Relationships with family and colleagues}

Expatriates and their families felt that it was difficult to keep in touch with their friends (Rosenbusch et al. 2015). Conflicting with co-workers was stressful for expatriates. To prevent such stress, selecting managers and providing training to both managers and expatriates before their assignments were helpful (Jassawalla et al. 2004). Many expatriates reported that the role of spousal adjustment was important (Gabel et al. 2005).

About $75 \%$ of business travellers and their families reported that they felt high stress levels. The assignment also negatively affected their children's behaviours (Espino et al. 2002). Expatriates' personal initiative as derived from supervisors, but not from co-workers, was related to job satisfaction, stress and performance (Stroppa and Spies 2011). Although there was no significant difference in the depression and anxiety scale between experienced and inexperienced workers on overseas assignments, white-collar workers in the experienced group received more supervisor support than the non-experienced group (Tsutsumi et al. 2005). Organisational support and well-established nurse/ doctor relationships were reported as being beneficial by Filipino nurses in the US (Hayne et al. 2009).

\section{Financial problems}

According to a study among expatriates living in Hong Kong, equity perception and appropriate assignments were positively associated with pay satisfaction (Shaffer et al. 
2013). Job insecurity was the major stress factor for expatriate nurses, which caused burnout and frustration (Karkar et al. 2015).

Wage inequalities, such as low pay and high workloads, were the main factor in work-related stress (Weishaar 2008). The job skills of immigrant workers were low as a result of low education status, which affected their job opportunities and fostered low-income status (Hayne et al. 2009). Many Filipino immigrant nurses in the US send money to their families in their home country, which was a major stress factor because this remittance was deducted from their living expenses (Connor and Miller 2014). A study among immigrant workers in the UAE found that poor income $(<1000$ UAE Dirham/month) was one of the risk factors for depression and suicidal ideation (Al-Maskari et al. 2011).

\section{Social inequality}

Non-standard wages, having limited choices and abuse from employers and local people were the factors in the perception of stress (Nilvarangkul et al. 2010).

Discrimination is often reported to be a stressor for foreign-born workers. Filipino immigrant nurses faced discrimination, bullying, alienation and resettlement problems in the process of adaptation to their new country (Connor and Miller 2014). Workers from less-developed countries tended to perceive discrimination from the host country, which can be a risk factor for depression (Negi 2012; Wadsworth et al. 2006; Ayalon 2010). African-Caribbean females who experienced racial discrimination tended to perceive this as part of work stress (Wadsworth et al. 2006). For Latino migrant workers, management fairness and supervisor support were strongly related to their well-being (Hoppe et al. 2009).

\section{Discussion}

The results of the present study can be greatly helpful in understanding the stress structure of working abroad and because there are many foreign-born workers all over the world. Few studies have elucidated foreign-born workers' stress structure; therefore, these findings in the present study can provide useful data. Because this structure is different from native workers' structure, particular attention is needed to manage foreign-born workers. From the present systematic review, six components of foreign-born workers' stress were extracted, which were communication, cultural differences in the workplace, daily life, relationships with family and colleagues, financial problems and social inequality. They can be thought of as the core components of the stress model.

In terms of workers' stress, there are two types: work stress and non-work stress. According to the National
Institute for Occupational Safety and Health (NIOSH), stressors such as physical workload, spending a long time at work, shift work and qualitative burden affect the risk of injury and illness; however, the range of the stress reactions depends on each workers' stress reduction capacity, which relates to factors such as age, sex, character, competence, support from one's boss and colleagues and familial factors (Hurrell and McLaney 1988). When the stress model is mentioned, non-work factors and stress reduction capacity should also be evaluated. In the present study, six components cover work stress such as communication and cultural differences in the workplace, non-work stress such as daily life and financial problems, and workers' stress reduction capacity such as relationships with family and colleagues and social inequality.

The most remarkable outcome of this systematic review was that six components were extracted. There was no study systematically evaluating the stress of foreign-born workers; therefore, the findings were highly valuable in the area of workers' acculturation studies. Black et al. (1991) suggested a model of acculturation, which has five factors (individual, job, organisational culture, organisational socialisation and non-work) that relate to the degree of adjustment. In contrast, there are six components (communication, cultural differences in the workplace, daily life, relationships with family and colleagues, financial problems and social inequality) extracted in the present study. Although most factors overlapped, Black's model did not include financial problems and social inequality. These factors are very important when workers from a less-developed country are assessed. In addition, previous theories were theoretically well-structured and well-organised, but they were not systematically developed. Because the present study was based on a systematic review, the components might be more comprehensive than previous theories on this point.

From the qualitative studies, it was found that fluency in the host country's language was an important factor in communication. Many participants complained about speaking the host country's language. However, surprisingly, there was no significant difference in language competence seen in the results of quantitative studies. Speaking a host country's language was not an important factor for foreign-born workers. Three reasons can be considered. First, workers may need to speak only when it is related to their job, and speaking their own language can be an advantage. Second, some assignments do not require employees (e.g. farm workers) to speak the host country's language. In addition, when the foreign-born worker's community is large, they can speak their own language. Third, workers who are reluctant to speak another country's language might not even go abroad. The important factor in the communication domain might be how workers are involved in the host country's community rather than the issue of language proficiency. Social relations 
were one of the mitigating factors in stress for international assignees (Gabel et al. 2005).

When it comes to occupational training, to prevent work acculturation failure, although the present study could not show evidence on whether the training should be done before or after workers arrive in the host country, the contents of training should include both daily life and business acculturation. Harrison and Hopkins (1967) developed the first design for cross-cultural training using organisational structure and a problem-solving strategy. From the 25-year review, six approaches were suggested: cultural awareness, interaction, language, didacticism and experiential training (Littrell et al. 2006).

Support from family and co-workers is important in mitigating foreign-born workers' stress levels. As part of the demand-control-support model, support is one of the most important factors in managing stress. The Health and Safety Executive also mentioned the importance of support when workers manage their stress (Health and Safety Executive 2005). There are many support resources for native-born workers, but there is a lack of support for foreign-born workers because they have moved to a new place. They need to participate in their new community and in social activities when they seek social support.

\section{Strengths and limitations}

The strength of the present study is that both work and acculturation stress were evaluated. This made it possible to systematically assess what the stress of working abroad was and its relevant factors. Few evidence-based studies have evaluated both work and acculturation stress; therefore, the present study is useful if we want to understand the structure of foreign-born workers' stress levels. The structure is similar to previous theories of acculturation, which supports the present study. In addition, the authors found two new risk factors, financial problems and discrimination, which were not mentioned in the previous theories. On the basis of the results of the present study, managers of foreign-born workers and workers themselves can ascertain what factors affect stress using the six extracted domains.

There are some limitations in the present study. First, this systematic review does not include enough evidence-based studies. Although, in the protocol, a GRADE evidence profile (GRADE Working Group 2004) and a meta-analysis were planned to be conducted, these could not be done because there was only one RCT. Furthermore, about onethird of the included studies were qualitative, which means there was a lack of deductive studies. Although the present study could propose the stress model, more experimental studies are needed to evaluate the model. Second, strong heterogeneity existed in the assessment method of stress among the included studies. The heterogeneity might be too inadequate to integrate the studies into a theory, so a new assessment tool needs to be developed. There are many tools for assessing acculturation, but few have been developed to assess acculturation related to work. Third, it is difficult to differentiate work stress and acculturation stress. Although there are many overlapping areas, stress of working abroad includes job stress; therefore, precise assessment of job stress is also needed. Finally, the search was conducted in November 2015. In 2016 and 2017, new studies reported that the supervisor's support is related to the vigour of migrant workers (Hoppe et al. 2017), migrant nurses experienced work role and culture differences (Zhong et al. 2017), and the state of qualifications was the main factor influencing mental state (Sato et al. 2016). In several years, this systematic review will need to be updated.

\section{Conclusion}

As international assignments and the number of immigrants increase, the importance of stress management among foreign-born workers also increases. There are many theories and assessment tools for acculturation, whereas theories and assessment tools for foreign-born workers' stress do not exist. Since foreign-born workers are suffering from acculturation and occupational stress, establishment of a model and development of a questionnaire are needed. To establish the model of foreign-born workers' stress, the present study was conducted. From the study, six components of foreignborn workers' stress were extracted.

Acknowledgements A part of this study was financially supported by Hospital Bando, Japan.

\section{Compliance with ethical standards}

Conflict of interest Authors declare that there are no conflicts of interest.

Open Access This article is distributed under the terms of the Creative Commons Attribution 4.0 International License (http://creativeco mmons.org/licenses/by/4.0/), which permits unrestricted use, distribution, and reproduction in any medium, provided you give appropriate credit to the original author(s) and the source, provide a link to the Creative Commons license, and indicate if changes were made.

\section{References}

Aalto AM, Heponiemi T, Keskimäki I, Kuusio H, Hietapakka L, Lämsä $\mathrm{R}$ et al (2014) Employment, psychosocial work environment and well-being among migrant and native physicians in Finnish health care. Eur J Public Health 24(3):445-451. https://doi.org/10.1093/ eurpub/cku021 
Adams BG, van de Vijver FJR (2015) The many faces of expatriate identity. Int J Intercult Relat 49:322-331

Alderete E, Vega WA, Kolody B, Aguilar-Gaxiola S (2001) Lifetime prevalence of and risk factors for psychiatric disorders among Mexican migrant farmworkers in California. Am J Public Health 90:608-614

Alkhadher O, Al-Naser H (2007) Assessing occupational stress, strain, and coping for North American teachers in Kuwait. Psychol Rep 99:681-690. https://doi.org/10.2466/pr0.99.3.681-690

Al-Maskari F, Shah SM, Al-Sharhan R, Al-Haj E, Al-Kaabi K, Khonji $D$ et al (2011) Prevalence of depression and suicidal behaviors among male migrant workers in United Arab Emirates. J Immigr Minor Health 13:1027-1032. https://doi.org/10.1007/s1090 3-011-9470-9

Arthur MB, Claman PH, DeFillippi JR (1995) Intelligent enterprise, careers. Acad Manag Exec 9(4):7-22

Ayalon L (2010) Intention to leave the job among live-in foreign home care workers in Israel. Home Health Care Serv Q 29:22-36. https ://doi.org/10.1080/01621424.2010.487037

Berry JW (1997) Immigration, acculturation, and adaptation. Appl Psychol Int Rev 46(1):5-34

Bhanugopan R, Fish A (2006) An empirical investigation of job burnout among expatriates. Pers Rev 35:449-468

Bhaskar-Shrinivas P, Harrison DA, Shaffer MA, Luk DM (2005) Input-based and time-based models of international adjustment: meta-analytic evidence and theoretical extensions. Acad Manag J 48(2):257-281

Black J, Mendenhall M, Oddou G (1991) Toward a comprehensive model of international adjustment: an integration of multiple theoretical perspectives. Acad Manag Rev 16(2):291-317

Brown DE, James GD (2000) Physiological stress responses in Filipino-American immigrant nurses: the effects of residence time, life-style, and job strain. Psychosom Med 62:394-400

Burkholder JD, Joines R, Cunningham-Hill M, Xu B (2010) Health and well-being factors associated with international business travel. J Travel Med 17:329-333. https://doi.org/10.111 $1 / \mathrm{j} .1708-8305.2010 .00441 . \mathrm{x}$

CASP (2013) Critical appraisal skills programme (CASP). http://www. casp-uk.net/. Accessed 04 Jan 2017

Cervantes RC, Padilla AM, de Snyder NS (1991) The Hispanic stress inventory: a culturally relevant approach to psychosocial assessment. Psychol Assess J Consult Clin Psychol 3(3):438-447

Cervantes RC, Fisher DG, Padilla AM, Napper LE (2016) The Hispanic stress inventory version 2: improving the assessment of acculturation stress. Psychol Assess 28(5):509-522. https://doi. org/10.1037/pas0000200

Chen G, Kirkman BL, Kim K, Farh CI, Tangirala S (2010) When does cross-cultural motivation enhance expatriate effectiveness? A multilevel investigation of the moderating roles of subsidiary support and cultural distance. Acad Manag J 53:1110-1130. https ://doi.org/10.5465/AMJ.2010.54533217

Connor JB, Miller AM (2014) Occupational stress and adaptation of immigrant nurses from the Philippines. J Res Nurs 19:504-515. https://doi.org/10.1177/1744987114536570

de Castro AB, Voss JG, Ruppin A, Dominguez CF, Seixas NS (2010) Stressors among Latino day laborers. A pilot study examining allostatic load. AAOHN J 58:185-196. https://doi.org/10.3928/08910 162-20100428-01

Deosthalee P (2002) Are Indian expatriates in Sultanate of Oman under stress? J Manag Psychol 17(6):523-528

Donlan W, Lee J (2010) Screening for depression among indigenous Mexican migrant farmworkers using the Patient Health Questionnaire-9. Psychol Rep 106:419-432. https://doi.org/10.2466/ pr0.106.2.419-432

Ea EE, Griffin MQ, L'Eplattenier N, Fitzpatrick JJ (2008) Job satisfaction and acculturation among Filipino registered nurses. J Nurs Scholarsh 40:46-51. https://doi.org/10. 1111/j.1547-5069.2007.00205.x

Espino CM, Sundstrom SM, Frick HL, Jacobs M, Peters M (2002) International business travel: impact on families and travellers. Occup Environ Med 59:309-322

Font A, Moncada S, Benavides FG (2012) The relationship between immigration and mental health: what is the role of workplace psychosocial factors. Int Arch Occup Environ Health 85(7):801-806. https://doi.org/10.1007/s00420-011-0724-6

Fujishiro K, Landsbergis PA, Diez-Roux AV, Stukovsky KH, Shrager S, Baron S (2010) Factorial invariance, scale reliability, and construct validity of the job control and job demands scales for immigrant workers: the multi-ethnic study of atherosclerosis. J Immigr Minor Health 13:533-540. https://doi.org/10.1007/s1090 3-010-9364-2

Gabel RS, Dolan SL, Cerdin JL (2005) Emotional intelligence as predictor of cultural adjustment for success in global assignments. Career Dev Int 10:375-395. https://doi.org/10.1108/1362043051 0615300

GRADE Working Group (2004) Grading quality of evidence and strength of recommendations. BMJ 328:1490-1494

Griffin J, Soskolne V (2003) Psychological distress among Thai migrant workers in Israel. Soc Sci Med 57:769-774

Grzywacz JG, Quandt SA, Chen H, Isom S, Kiang L, Vallejos Q, Arcury TA (2010) Depressive symptoms among Latino farmworkers across the agricultural season: structural and situational influences. Cult Divers Ethn Minor Psychol 16:335-343. https:// doi.org/10.1037/a0019722

Gullahorn JT, Gullahorn JE (1963) An extension of the U-curve hypothesis. J Soc Issues 19(3):33-47. https://doi. org/10.1111/j.1540-4560.1963.tb00447.x

Harrison R, Hopkins RL (1967) The design of cross-cultural training: an alternative to the university model. J Appl Behav Sci $3: 431-460$

Hayne AN, Gerhardt C, Davis J (2009) Filipino nurses in the United States: recruitment, retention, occupational stress, and job satisfaction. J Transcult Nurs 20:313-322. https://doi.org/10.1177/10436 59609334927

Health and Safety Executive (2005) What are the management standards. http://www.hse.gov.uk/stress/standards/. Accessed 04 Jan 2017

Hechanova R, Beehr TA, Christiansen ND (2003) Antecedents and consequences of employees' adjustment to overseas assignment: a meta analytic review. Appl Psychol Int Rev 52(2):213-236

Higgins J, Green S (2011) Cochrane handbook for systematic reviews of interventions. The Cochrane Collaboration, 2011. http://handb ook.cochrane.org/. Accessed 04 Jan 2017

Hiott AE, Grzywacz JG, Davis SW, Quandt SA, Arcury TA (2008) Migrant farmworker stress: mental health implications. J Rural Health 24:32-39. https://doi.org/10.1111/j.1748-0361.2008.00134 .x

Hoppe A, Heaney CA, Fujishiro K (2009) Stressors, resources, and well-being among Latino and White warehouse workers in the United States. Am J Ind Med 53:252-263. https://doi.org/10.1002/ ajim. 20752

Hoppe A, Toker S, Schachler V, Ziegler M (2017) The effect of change in supervisor support and job control on change in vigor: differential relationships for immigrant and native employees in Israel. J Organ Behav 38(3):391-414. https://doi.org/10.1002/job.2151

Hovey JD, Magana CG (2002) Psychosocial predictors of anxiety among immigrant Mexican migrant farmworkers: implications for prevention and treatment. Cult Divers Ethn Minor Psychol 8:274-289

Huang FF, Yang HH (2011) The effects of nationality differences and work stressors on work adjustment for 
foreign nurse aides. BMC Health Serv Res 11:192. https://doi. org/10.1186/1472-6963-11-192

Hurrell JJ, McLaney MA (1988) Exposure to job stress: a new psychometric instrument. Scand J Work Environ Health 14(suppl 1):27

Jassawalla A, Truglia C, Garvey J (2004) Cross-cultural conflict and expatriate manager adjustment: an exploratory study. Manag Decis 42:837-849. https://doi.org/10.1108/00251740410550916

Karkar A, Dammang ML, Bouhaha BM (2015) Stress and burnout among hemodialysis nurses: a single-center, prospective survey study. Saudi J Kidney Dis Transpl 26(1):12-18

Kawai N, Mohr A (2015) The contingent effects of role ambiguity and role novelty on expatriates' work-related outcomes. Br J Manag 26:163-181. https://doi.org/10.1111/1467-8551.12089

Kim SY, Park JE, Lee YJ, Seo HJ, Sheen SS, Hahn S et al (2013) Testing a tool for assessing the risk of bias for nonrandomized studies showed moderate reliability and promising validity. J Clin Epidemiol 66:408-414. https://doi.org/10.1016/j.jclinepi.2012.09.016

Lazarus RS (1997) Acculturation isn't everything. Appl Psychol 46(1):39-43

Lee H, Ahn H, Miller A, Park CG, Kim SJ (2012) Acculturative stress, work-related psychosocial factors and depression in Korean-Chinese migrant workers in Korea. J Occup Health 54:206-214

Lee H, Chae D, Wilbur J, Miller A, Lee K, Jin H (2014) Effects of a 12 week self-managed stretching program among Korean-Chinese female migrant workers in Korea: a randomized trial. Jpn J Nurs Sci 11:121-134. https://doi.org/10.1111/jjns.12010

Liberati A, Altman D, Tetzlaff J, Mulrow C, Gotzsche P, Loannidis J et al (2009) The PRISMA statement for reporting systematic reviews and meta-analyses of studies that evaluate health care interventions: explanation and elaboration. J Clin Epidemiol 62(10):e1-e34. https://doi.org/10.1016/j.jclinepi.2009.06.006

Littrell LN, Salas E, Hess KP, Paley M, Riedel S (2006) Expatriate preparation: a critical analysis of 25 years of cross-cultural. Hum Resour Dev Rev 5(3):355-388

Luxon T, Peelo M (2009) Academic sojourners, teaching and internationalisation: the experience of non-UK staff in a British university. Teach High Educ 14:649-659. https://doi.org/10.1080/13562 510903315233

Lysgaard S (1955) Adjustment in a foreign society: Norwegian Fulbright grantees visiting the United States. Int Soc Sci Bull 7:45-51

Mendenhall M, Oddou G (1985) The dimensions of expatriate acculturation: a review. Acad Manag Rev 10(1):39-47

Negi NJ (2012) Battling discrimination and social isolation: psychological distress among Latino day laborers. Am J Community Psychol 51:164-174. https://doi.org/10.1007/s10464-012-9548-0

Nilvarangkul K, Rungreangkulkij S, Wongprom J (2010) Perception of stress in Laotian migrant workers in Thailand. J Immigr Minor Health 12:678-682. https://doi.org/10.1007/s10903-009-9315-y

Office for National Statistics (2015) Travel trends, 2014. http://www. ons.gov.uk/ons/dcp171776_403337.pdf. Accessed 14 Oct 2017

Okamoto K, Teo S (2011) Convergence and divergence of role stress experience of locally hired Japanese and non-Japanese host country staff: a qualitative study. Int J Hum Resour Manag 22:218-231. https://doi.org/10.1080/09585192.2011.538984

Pasca R, Wagner SL (2012) Occupational stress, mental health and satisfaction in the Canadian multicultural workplace. Soc Indic Res 109:377-393. https://doi.org/10.1007/s11205-011-9907-5

Rogler LH, Cortes DE, Malgady RG (1991) Acculturation and mental health status among Hispanics: convergence and new directions for research. Am Psychol 46:585-597
Rosenbusch K, Cerny LJ, Earnest DR (2015) The impact of stressors during international assignments. Cross Cult Manag 22:405-430. https://doi.org/10.1108/CCM-09-2013-0134

Sato F, Hayakawa K, Kamide K (2016) Investigation of mental health in Indonesian health workers immigrating to Japan under the Economic Partnership Agreement. Nurs Health Sci 18(3):342-349. https://doi.org/10.1111/nhs.12275

Shaffer M, Singh B, Chen YP (2013) Expatriate pay satisfaction: the role of organizational inequities, assignment stressors and perceived assignment value. Int J Hum Resour Manag 24:2968-2984. https://doi.org/10.1080/09585192.2013.763838

Shen BJ, Takeuchi DT (2001) A structural model of acculturation and mental health status among Chinese Americans. Am J Community Psychol 29(3):387-418

Silbiger A, Pines AM (2014) Expatriate stress and burnout. Int J Hum Resour Manag 25:1170-1183. https://doi.org/10.1080/09585 192.2013.824911

Snipes SA, Thompson B, O'Connor K, Godina R, Ibarra G (2007) Anthropological and psychological merge: design of a stress measure for Mexican farmworkers. Cult Med Psychiatry 31:359 388. https://doi.org/10.1007/s11013-007-9054-2

Stahl GK, Caligiuri P (2005) The effectiveness of expatriate coping strategies: the moderating role of cultural distance, position level, and time on the international assignment. J Appl Psychol 90:603615. https://doi.org/10.1037/0021-9010.90.4.603

Stroppa C, Spies E (2011) International assignments: the role of social support and personal initiative. Int J Intercult Relat 35:234-245. https://doi.org/10.1016/j.ijintrel.2010.09.008

Tsai JH, Salazar MK (2007) Occupational hazards and risks faced by Chinese immigrant restaurant workers. Fam Community Health 30:S71-S79. https://doi.org/10.1097/01.fch.0000264882.73440 .20

Tsutsumi A, Izutsu T, Sakami S, Miyazaki T, Wakai S, Kawamura N (2005) Long-term influence of working abroad on returnees' mental health. J R Soc Promot Health 125:281-286

Wadsworth E, Dhillon K, Shaw C, Bhui K, Stansfeld S, Smith A (2006) Racial discrimination, ethnicity and work stress. Occup Med 57:18-24. https://doi.org/10.1093/occmed/kq1088

Wang X, Kanungo RN (2004) Nationality, social network and psychological well-being: expatriates in China. Int J Hum Resour Manag 15:775-793. https://doi.org/10.1080/0958519042000192942

Wang M, Takeuchi R (2007) The role of goal orientation during expatriation: a cross-sectional and longitudinal investigation. J Appl Psychol 92:1437-1445. https://doi.org/10.1037/0021-9010.92.5.1437

Weishaar H (2008) Consequences of international migration: a qualitative study on stress among Polish migrant workers in Scotland. Public Health 122:1250-1256. https://doi.org/10.1016/j. puhe.2008.03.016

Winkelman SB, Chaney EH, Bethel JW (2013) Stress, depression and coping among Latino migrant and seasonal farmworkers. Int J Environ Res Public Health 10:1815-1830. https://doi.org/10.3390/ ijerph10051815

Zahid MA, Fido AA, Alowaish R, El-Motaal Mohsen MA, Razik MA (2003) Psychiatric morbidity among housemaids in Kuwait III: vulnerability factors. Int J Soc Psychiatry 49(2):87-96. https:// doi.org/10.1177/0020764003049002002

Zhong Y, McKenna L, Copnell B (2017) What are Chinese nurses' experiences whilst working overseas? A narrative scoping review. Int J Nurs Stud 74:101-111. https://doi.org/10.1016/j.ijnur stu.2017.06.009 